\title{
REFLEXIONES CRITICAS SOBRE LA HISTORIA DEL PENSAMIENTO ECONOMICO A PROPOSITO DE UN LIBRO *
}

\author{
VICTORIANO MARTIN MARTIN \\ Universidad Complutense. Madrid
}

Las líneas que siguen pretenden algo más que dar cuenta del contenido de una obra de historia del pensamiento económico. Intentan realizar algunas puntualizaciones sobre algunos aspectos del libro que se comenta, que parecen no ajustarse a la letra escrita por los pensadores cuyas obras se analizan, y digo sobre la letra escrita, porque sobre lo que verdaderamente quisieron decir es harto difícil especular ya que eso se lo tendríamos que preguntar a ellos mismos y, en este caso, las posibilidades de respuesta serían, evidentemente, nulas. Dichas puntualizaciones, que en manera alguna pretenden ser exhaustivas, sí tienen una finalidad pedagógica, y ello porque es muy posible que dadas las características de la obra, de síntesis completa de la historia del pensamiento económico, sea utilizada como libro de consulta por alumnos de licenciatura de las Facultades de Ciencias Económicas. No menos importante es la intención de cooperar a un mayor esclarecimiento de las teorías de los economistas del pasado.

En primer lugar, expondremos una síntesis muy breve del contenido del libro. A continuación haremos un recorrido por el mundo de los manuales de historia del pensamiento económico. Finalmente, pasaremos a la crítica, que será respaldada por los textos originales de los autores objeto de estudio. No hace falta resaltar que sentimos un gran respeto por el esfuerzo investigador del autor y que en manera alguna pretendemos que sea empañado por esta nota.

En la portada del libro reza una especie de subtítulo, en letra muy pequeña: «Exposición sencilla y sistemática de las principales soluciones que el hombre ha ido dando a lo largo de la historia al problema económicow. En el prólogo, el autor vuelve a señalar los objetivos que pretende cumplir la obra, señalando «la finalidad de mostrar la dimensión histórica de la economía» me-

* Miguel A. Martínez Echevarría, Evolución del pensamiento económico, EspasaCalpe, Madrid, 1983, 404 pp. 
diante una «exposición sencilla y lo más completa posible de las principales corrientes del pensamiento económico".

Se abre el primer capítulo con una síntesis del pensamiento económico en la Grecia clásica, y el capítulo XXII termina con el tratamiento de la teoría económica de Milton Friedman, repasando prácticamente la totalidad de los autores más representativos de la historia del pensamiento económico, así como las principales corrientes de pensamiento. Trata el mercantilismo, la fisiocracia, la economía clásica, las críticas a la escuela clásica, Marx, el marginalismo y la reflexión económica del siglo xx.

Un aspecto importante a resaltar es que más de la mitad del libro -en torno a 200 páginas - está dedicado a autores que desarrollan gran parte de su actividad intelectual, o la totalidad de la misma, en el siglo xx. Pero, además, tal vez sea a partir del capítulo XIV la parte del índice cuya organización ofrezca menos reparos en cuanto a lo que pudiéramos denominar organización convencional de la disciplina, ya que, siempre desde el punto de vista convencional, existe una coherencia clara entre el título general del capítulo y los títulos de los distintos epígrafes que lo desarrollan.

Pero la tarea de escribir una historia del pensamiento económico es ardua y, además, las teorías de los economistas del pasado se prestan fácilmente a distintas interpretaciones. La tarea se dificulta aún más cuando existe en el mercado un número ya importante de manuales, algunos de ellos difícilmente mejorables, tanto en la calidad científica de la síntesis como en su extensión y comprensión para estudiantes que se inician en el estudio de esta disciplina.

Pensamos que la historia del pensamiento económico debe contar la historia del progreso científico de la economía. A sabiendas de que es necesario estudiar los problemas que quisieron resolver los científicos o los fenómenos que intentaron explicar para comprender la historia de la ciencia, creemos que la tarea del historiador debe abarcar algo más que el análisis ahistórico de las teorías económicas del pasado; los escenarios socioeconómicos en que surgen las teorías y las circunstancias personales y de todo tipo en que desarrollaron su trabajo los economistas deben ser objeto de especial atención. Ahora bien, el tipo de historia que se haga dependerá del esquema general metodológico que se defienda.

De ahí que, como señala Pedro Schwartz, puedan clasificarse las distintas maneras de escribir historia del pensamiento económico sobre la base de la metodologia de los historiadores. Sin intentar ser exhaustivos, ya que el tratado de los aspectos metodológicos de la historia del pensamiento económico queda fuera de nuestro objetivo, existen diversas aproximaciones a la disciplina, diversidad que se adivina por las distintas apelaciones, que obedecen, a su vez, a una diferenciación de contenido. El profesor Schwartz habla de 
cuatro'. Dejando a un lado la apelación historia de las opiniones económicas, considerada como la colección de ideas con algún contenido económico compartidas por no profesionales, nos vamos a referir a otros tres, asociados a importantes tratados sobre el tema. En primer lugar, la historia de las doctrinas económicas, cuya connotación principal sería la importante carga ideológica que conlleva, así como las referencias históricas a puntos particulares de doctrina. Algunas de estas características diferencian una serie de obras que se vienen publicando desde mediados del xviıl. Ejemplos de esta forma de escribir historia del pensamiento económico los encontramos, siguiendo el orden cronológico de su aparición, en Dupont de Nemours, De l' origine et progrès d'une sciencie nouvelle (1769) (Origen y progreso de una ciencia nueva). Esta obra es una especie de resumen de otro tratado más amplio de PierrePaul Mercier de la Riviere, L'Ordre naturel et essentiel des sociétés politiques (1767) (El orden natural y esencial de las sociedades políticas). John Ramsay McCulloch, Litcrature of Political Economy (1845) (Literatura de la economía política). K. Marx, Teorias sobre la plusvalía, publicado por primera vez por Karl Kautsky en tres volúmenes entre 1905 y 1910. John Maynard Keynes, en el capítulo 23 de The General Theory of Employement Interest and Money (1936) (Teoría general de la ocupación, el interés y el dinero), titulado «Notas sobre el mercantilismo, las leyes sobre la usura, el dinero sellado y las teorías del subconsumo», también escribe una historia característica de las doctrinas económicas. Finalmente, por no hacer una lista demasiado larga, podemos citar la obra de Eric Roll, A History of Economic Thought (1939) (Historia del pensamiento económico).

En segundo lugar, la historia del análisis económico, caracterizada por lo que podíamos denominar la coherencia interna de las «herramientas» de los economistas, por el estudio del progreso analítico. La obra de Joseph Alois Schumpeter, History of Economic Analysis (1954) (Historia del análisis económico), responderá a esta concepción.

En tercer lugar, la historia de las teorías, como diferenciada de la historia del análisis; no se trata ahora ya de la historia de los instrumentos analíticos, de la "caja de herramientas» de los economistas, sino de la historia de las teorías económicas. Una obra claramente representativa de esta aproximación es la del profesor Mark Blaug, Economic Theory in Retrospect (1968) (Teoría económica en retrospección).

Las clasificaciones también pueden ajustarse a las grandes corrientes metodológicas. Así, parece que la obra de Schumpeter está concebida bajo el modelo deductivista. La obra de uno de los grandes fundadores de la economía histórica alemana, Wilhelm Roscher, El pensamiento económico inglés de los

' P. SCH Wartz y T. S. Hollander, "Teaching the History of Economics Thought: Report of a Symposium at Bristol», 1973, HOPE, vol. 7, núm. 1, 1975. 
siglos XVI y XVII (1851-1862), se ajusta al esquema inductivista, cayendo, además, en el campo de la historia de las doctrinas ${ }^{2}$. Eric Roll escribió $A$ History of Economic Thought bajo la influencia relativista. Mientras que a la óptica falsacionista responde el libro de Mark Blaug, Economic Theory in Retrospect. William Barber, siguiendo a Lakatos, concibe la historia del pensamiento económico como una sucesión de «programas de investigación», según queda reflejado en su obra $A$ History of Economic Thought (1967) (Historia del pensamiento económico). Una obra que compagina en su exposición el contexto de validación con el contexto de descubrimiento es la de Henry William Spiegel, The Growth of Economic Thought (1973) (El desarrollo del pensamiento económico).

Los párrafos anteriores explican el que se eche de menos una introducción o un prólogo más amplio en que se justificara, por una parte, la concreta elaboración del índice y, por otra, el enfoque que se da al peculiar desarrollo del contenido. Justo es decirlo: por lo que se refiere al índice, aunque no sistemáticamente, hay algún intento de justificación en algunas introducciones de los capítulos. Sin embargo, el autor, que nos está hablando constantemente de "concepción metodológica», nos ha privado de ese capítulo introductorio en que se nos explique la suya.

El autor, que en la introducción ha hecho referencia a la importancia del contexto de descubrimiento, situará a los pensadores en el tiempo con la simple indicación del año de nacimiento y de la muerte colocados a continuación del nombre, lo que en una concepción de este tipo resulta insuficiente. Pero, al no exponernos su concepción metodológica, tenemos que conjeturar sus pretensiones. Pues lo que por la forma aparenta ser una historia del análisis económice o una historia de las teorías, por su fondo podría más bien clasificarse como una historia de las doctrinas económicas. Igualmente, se nos priva de bibliografía y de notas a pie de página. En manera alguna queda justificada esta ausencia. Las referencias bibliográficas podían muy bien haberse llevado al final del libro o al final de los capítulos. De esta forma se hubiera evitado el tedio del lector perezoso, al tiempo que quedaría satisfecha la inquietud de los más curiosos.

Pero, además, la utilización del criterio temporal en la agrupación de los autores no siempre resulta pedagógica y sí, a veces, metodológicamente incompatible. Por sólo citar un ejemplo, es dudoso que $\mathrm{H}$. von Thünen encaje bien bajo el epígrafe general de «Madurez y agotamiento de una escuela», refiriéndose a la clásica, pero la presencia de J. S. Mill en el mismo capítulo complica aún más las cosas. Tal vez fuera conveniente demostrar la no plena originalidad (p. 88) de Thünen, si tal cosa es cierta; pues, hasta el momento, parece p. 381 .

2 J. A. Schumpeter, History of Economic Analysis, Oxford University Press, 1954, 
que es Thünen quien ostenta el «derecho de fundador del análisis marginal» ${ }^{3}$. El culto propietario agrícola alemán se adelantó en casi cincuenta años a la generalización de la teoría de la distribución basada en la productividad marginal.

En el índice es notoria la ausencia casi absoluta de toda referencia a autores españoles. Tal ausencia es difícilmente justificable cuando se señala a Jean Bodin como «el formulador definitivo de la teoría cuantitativa del dinero» (p. 23). No son suficientes las escuetas menciones a Tomás de Mercado, Azpilcueta y Soto. Bodin publicó su Response à $M$. de Malestroit en 1568 y Les six livres de la Republique en 1576. Domingo de Soto publica en Salamarica, en 1556, De iustitia et iure, y Martín de Azpilcueta su Comentario resolutorio de cambios, también en 1556. La lectura de la cuestión XII del libro VI de la obra de Domingo de Soto y el Comentario de Azpilcueta ${ }^{4}$ nos advierten de algo más que de insinuaciones.

Aunque los autores medievales habían sentado las bases de la teoría cuantitativa y Copérnico, en su trabajo Monetae Cudendae Ratio, preparado en 1519 y expuesto ante la Asamblea de Polonia en 1522, afirmaba que *el dinero se deprecia, sobre todo, cuando se acuña en exceso" ${ }^{5}$, parece más justo hablar de los doctores escolásticos españoles del siglo XVI como verdaderos autores de la primera formulación sistemática de la teoría "cantidad de dineron de los precios.

Pero, sin pretender ser exhaustivo, es necesario referirse a algunos ejemplos más en los que la interpretación del autor plantea problemas importantes, aclarando previamente que no se mencionarán aquellos aspectos $o$ aportaciones al análisis económico de los pensadores omitidos en el texto, ya que pensamos que tales ausencias, por muy importantes que éstas sean, podrían justificarse en una obra de las características como la que nos ocupa.

Comenzaremos refiriéndonos al caso de David Hume (pp. 37-38). Cuando menos, es arriesgada la conclusión de que "la contribución más importante* de Hume es "la idea de que la prosperidad y una moderada tasa de inflación no sólo no son incompatibles, sino complementarias» (p. 38). David Hume dedica la mayor parte de su ensayo Of Money (Del dinero) a demostrar que «el dinero no es sino la representación del trabajo y de las cosas necesarias

${ }^{3}$ M. Blaug, Economic Theory in Retrospect, Cambridge University Press, 1978, p. 335.

- Domingo DE Soto, De iustitia et iure libri decem, Salamanca, 1556. Edición biliogüe: De la justicia y del derecho, Instituto de Estudios Politicos, Madrid, 1968, 5 vols. Cito por esta edición, vol. III, libro VI, cuestión XII, pp. 591 y ss. Martín de AzPILcuera, Comentario resolutorio de cambios, Salamanca, 1556. Edición del CSIC de 1965 , pp. $74 \mathrm{y}$ ss.

5 N. Copérnico, «Monetae cudendae ration, incluido en L. R. Branch w, Ecrits notables sur la monnaie, 2 vols., Félix Alcan, París (1934). Citado por Manuel Jeaús Gont ZÁLEZ y Juan DEL Hoyo, «Dinero y precios en la España del siglo Xvi, una confirmación de las tesis de Hamilton», Moneda y Crédito, núm. 166, septiembre 1983, p. 13. 
para la vida y que sirve sólo para tasar y estimar estas cosas. Allí donde el dinero abunda más se necesita una gran suma para representar la misma cantidad de bienes. De esto se deduce que no se debe considerar el bienestar o malestar de una nación por la mayor abundancia de dinero que ésta posea» ".

Sólo unas cuantas líneas dedica Hume a los efectos estimulantes que tiene sobre la actividad económica el «aumento del oro y de la plata», dejando claro que «no es más que en el intervalo o situación intermedia entre la adquisición de la moneda y el alza de los precios cuando el aumento de la cantidad de oro y plata es favorable a la industria» ${ }^{7}$, y previamente nos ha advertido de los peligros de una gran cantidad de dinero capaz de perjudicar a una nación en su comercio con el exterior ${ }^{8}$, sin duda en su intento de desacreditar a los mercantilistas, y ello a pesar de que Keynes, en la nota 3 de la página 343 del capitulo 23 de The General Theory, al fijarse en el texto que estamos comentando, señale que David Hume «todavía tenía lo bastante de mercantilista», aunque «tenía pie y medio en el mundo clásico» ${ }^{9}$.

El apartado sobre el tratamiento del «comercio internacional» también ofrece serios reparos. El ensayo de Hume Of the Balance of Trade (De la balanza de comercio), con su teoría del specie flow mechanism, al aplicar la teoría «cantidad de dinero» de los precios al ccmercio exterior, obtuvo el más sólido argumento contra las creencias mercantilistas.

Tampoco el gran amigo de David Hume, Adam Smith, sale muy bien parado en el libro; uno tiene la impresión, cuando el autor se refiere a la filosofía económica de Adam Smith, de que se está refiriendo a Mandeville. La idea de que Smith, «que casi ha convertido egoísmo y naturaleza humana en sinónimos, constituye el propio interés en la única fuerza bruta que hace mover la maquinaria económica» (p. 53), a todas luces encaja mejor en el contenido de The Fable of Bees (La fábula de las abejas), de Mandeville, que en la Theory of Moral Sentiments (Teoría de sentimientos morales), de Adam Smith, obra ésta que, entre otros objetivos, tenía el de rebatir las ideas de Mandeville. Con su teoría de la simpatía y del espectador imparcial, Smith defiende la existencia de sentimientos más ncbles y elevados que «la única fuerza bruta» a la que se refiere el autor. El contenido de la Wealtb of Nations (Riqueza de las naciones) no queda reflejado bajo el epígrafe «El mecanismo de la mano invisible». Pero el autor, en la página 112, va todavía mucho más lejos en la asimilación de A. Smith a Mandeville cuando, al referirse a la ética de Adam Smith, afirma que el "vicio privado - la avaricia y el egoísmo- era el fundamento del bienestar común». El juicio no puede parecerse más al título que

- David Hume, Writings on Economics, Ed. Eugene Rotwein, Nelson, 1955, p. 37.

7 Ibidem, p. 38.

I lidem, p. 34.

- J. M. KEYNES, The General Theory of Employement, Interest and Money, en los Collected Writings, vol. VII, MacMillan St. Martin Press, 1973, p. 343. 
rezaba en la edición de 1714 de la obra de Mandeville, The Fable of Bees: or Private Vices Public Benefits (La fábula de las abejas: o vicios privados beneficios públicos).

Por lo que se refiere al tratamiento de la teoría de la población de Malthus, también ofrece algunos reparos. Es cierto que la introducción en la segunda edición del Essay, publicada en 1803, del freno de la restricción moral hace irrefutable la teoría, ya que ésta es aplicable a cualquier movimiento de la población y prácticamente la convierte en una tautología. Sin embargo, la teoría de Malthus tuvo consecuencias analíticas muy importantes en la economía clásica, y no sólo «en los ambientes vulgarizadores del pensamiento económico» (p. 67), a no ser que como tales consideremos a David Ricardo y J. S. Mill, sobre el que convendrá también realizar algunas puntualizaciones. Pero, además, la línea de pensamiento sobre el comportamiento de la población, que, arrancando del Essai sur la nature du commerce en géneral (Ensayo sobre la naturaleza del comercio en general), de Cantillon, pasa a la Wealth of Nations, de Adam Smith, que es de donde la tomó Malthus, y que culminaría en An Essay on the Principle of Population, de 1798, abriría otra línea de pensamiento que continúa dando excelentes frutos a raíz de la publicación, en 1859, de On the Origin of Species (Sobre el origen de las especies), de Ch. Darwin. Y todo ello a pesar del "aberrante e inadecuado pensamiento de Malthus» (página 66). Tras analizar el contenido de la edición de 1803, rebosante por todas partes de material estadístico y empírico, uno tiene que dudar de la tajante afirmación que en la misma página 66 se realiza de que Malthus «nunca dispuso, ni remotamente, de los adecuados instrumentos estadísticos que dieran un mínimo de fiabilidad empirica a su dramática, pero falsa, exposición».

Por lo que se refiere a David Ricardo, al menos dos veces aparece como crítico de la ley de Say (pp. 259 y 277). Pero a Ricardo no le preocupaban tanto les problemas de sobreproducción como la posibilidad de conseguir alimentos baratos. Ricardo no ponía en duda la ley de Say; era un claro defensor de la misma. Como muestra de ello puede verse el capítulo 21 de los Principles y las notas al capítulo VII de los Principles of Political Economy, de Malthus, así como un conjunto de cartas que intercambia con su amigo Malthus, fundamentalmente las correspondientes a las siguientes fechas: 4-V-1820, 4-IX-1820, 9-X-1820, 24-XI-1820, 29-XI-1820, 9-VII-1821 y 21VII-1821 ${ }^{10}$.

Al referirse a J. S. Mill como al «último de los clásicos», afirma que «es indudable que este autor merece este calificativo no tanto por su personal aportación a la teoría económica, que fue más bien escasa, y poco importante...» (p. 89). Es cierto que Mill ha sido considerado como un economista mediocre,

${ }^{10}$ The Works and Correspondence of David Ricardo, Ed. Piero Sraffa, M. H. Dobb, Cambridge University Press, 1951, vols. I, II, VIII y IX. 
tal vez porque, como ha señalado Blaug, «evita cuidadosamente pregonar ninguna originalidad analítica, aunque hubiera podido hacerlo» ". Pero, efectivamente, en la actualidad resulta arriesgado mantener aquella presunción, y un tratadista de la talla de Stigler no ha dudado en afirmar que «en función de teorías identificables fue uno de los economistas más originales en la historia de la ciencia" ${ }^{12}$. La aseveración de Stigler está perfectamente dncumentada con textos tanto de los Principles of Political Economy (1848) como de los Essays on Some Unsettled Questions of Political Economy (1844).

Todo lo cual hace que podamos considerar a J. S. Mill como el economista inglés más importante de mediados del siglo xIx.

No parece del todo cierto que, como se señala en el capítulo $X$, al tratar el nacimiento del marginalismo, se abandone, casi totalmente, la cuestión de la distribución; al contrario, parece que la escuela de la productividad marginal proporcionó un notable avance a la teoría de la distribución al integrarla en una teoría general de los precios. Harry Johnson señaló «que la teoría de los precios de los factores y de la distribución de la renta es sólo un aspecto de la teoría general de los precios y de la teoría del equilibrio general» ${ }^{13}$. Los marginalistas manifestaron explícitamente que la «distribución» del producto entre los factores que contribuyen al mismo implica una retribución por sus servicios productivos y que esta retribución es también un precio, y de ahí que lo que podemos denominar, en expresión del profesor Castañeda, «la teoría de la formación de las rentas" no sea otra cosa que un caso particular de la formación de los precios ${ }^{14}$.

Ya señalábamos más arriba las tempranas aportaciones de Von Thünen en este campo. Jevons aplicó la teoría de la productividad marginal del capital para explicar su remuneración, aunque, justo es decirlo, no aplicó el mismo razonamiento a los salarios y la renta.

La teoría de la imputación de los austríacos consideraba la distribución como el proceso por el cual el valor de la utilidad del producto se imputaba a los factores. Walras incluyó la teoría de la distribución basada en la productividad marginal en su formulación del equilibrio general. Marshall, en el capítulo I del libro IV, expone una teoría de la distribución basada en la productividad marginal. Los nombres de Wicksteed en Inglaterra, J. B. Clark en América y de Wicksell en Suecia son otros tantos ejemplos de interés por el

" Mark Blaug, Economic Theory in Retrospect (1978), p. 187.

12 G. J. StIGLer, Essays in the History of Economics (1965). La cita se refiere a la edición en castellano: Historia del Pensamiento Económico, El Ateneo, Buenos Aires, 1979, p. 4.

${ }_{13}$ Harty G. Johnson, The Theory of Income Distribution, Gray-Mills Publishing, Londres. La cita se refiere a la edición castellana: Teoría de la distribución de la renta, Tecnos, Madrid, 1981, p. 16.

${ }^{14}$ José Castañedn, Lecciones de Teoría Económica, Aguilar, 1972, p. 597. 
problema de la distribución en la corriente de pensamiento que se generaliza a partir de la década de 1870 .

Pero entendemos que se han dado ejemplos suficientes para advertir al lector de algunos reparos al enfrentarse con la obra que nos ocupa. No nos queda sino llamar la atención de la necesidad y conveniencia de discutir temas de la envergadura del que venimos tratando en un marco más amplio y en el que tomen parte los especialistas de la disciplina. 